\title{
Ecological Restoration Modes of Soil and Water Conservation on the Mining Wasteland in Northern Grassland
}

\author{
Rong Hao*, Shan Dan and He Jingli \\ Institute of Water Resources for Pastoral Area, Ministry of Water Resources of China, Hohhot, Inner Mongolia, 010020, China
}

\begin{abstract}
Taking the mining wasteland formed in Xilinguole grassland as the research object, the ecological restoration mode of the soil and water conservation on mining wasteland was studied in the grassland. A test of water and soil conservation measures was conducted according to the characteristics of soil erosion, natural climate and etc., with the purpose of quickly restoring the damaged vegetation in mining wasteland and reducing soil erosion. The results showed four ecological restoration modes were used for the restoration on the mining wasteland, including "shrub", "shrub + grass", "ecological bag + grass" and "sand barriers + grass". Two ecological restoration modes which was "shrub + grass" and "sand barriers + grass", made the plant coverage reach more than $60 \%$, the amount of wind erosion was less than $8.0 \mathrm{t} / \mathrm{hm}^{2}$, the amount of water erosion was less than $3900 \mathrm{t} / \mathrm{km}^{2} \bullet \mathrm{a}$, the effect of soil and water conservation and ecological restoration was better, and the cost of economic input was lower.
\end{abstract}

\section{Introduction}

Inner Mongolia grassland is not only the largest natural pasture and animal husbandry production base, but also an important natural ecological barrier in China. In recent years, the energy industry based on coal and electricity has developed rapidly in grassland of Inner Mongolia and infrastructure construction has continued to increase. The ecological environment of the grassland and the production and life of farmers and herdsmen have inevitably been greatly affected. Construction activities such as mining and town construction have occupied and destroyed large areas of grasslands, changed the original appearance of grasslands, damaged the soil structure, and exposed large areas of the ground to make the grassland landscapes incomplete[1]. Soil and water loss in the construction area of grassland engineering projects is the type of soil and water loss caused by human production and construction activities as the main external force, which is the destruction and loss of resources and land productivity[2]. This erosion is a typical artificial accelerated erosion[3-5].mining wasteland is one of the typical representatives of engineering erosion[6]. At present, the ecological restoration technology and research of soil and water conservation in mining areas was carried out by domestic and foreign scholars. The results of foreign research mainly include the impact mechanism of mining on site conditions, ecological and comprehensive management of abandoned land, and physical restoration, biological reclamation, Phytoremediation technology, anti-erosion reclamation technology, etc[7]. The United States, Canada, Australia, France and other developed countries have basically achieved comprehensive restoration of land, environment and ecology[8]. The United States focuses on water and forest land restoration, Australia focuses on grassland management and restoration, and France and other European countries focus on abandoned land restoration[9-11]. China's mine development in semi-arid grasslands lack comprehensive and effective technical means and governance modes for the comprehensive management of soil erosion, and the scientific and technological foundation is very weak[12.13]. The study is based on the experimental study of the ecological restoration mode of the soil and water conservation on mining wasteland in the grassland area. Appropriate restoration modes are configured for different landform types based on the principles of ecological priority, scientificity, operability, and nearnatural restoration. The research results provide technical support and scientific basis for the prevention and control of water and soil erosion and ecological restoration on mining wasteland in grassland.

\section{Materials and methods}

\subsection{Experimental design}

The study area was located at the Bilihe gold mine in Xilinguole League, Inner Mongolia. The mining wasteland was located in the northeast of the gold mine and covered an area of $30 \mathrm{hm}^{2}$. It is a stepped landform with platforms and slopes distributed and the relative height is $100 \mathrm{~m}$. The height of each step is about $20 \mathrm{~m}$. The waste rock was mixed with soil and then discharged to the dump and then covered with soil $50 \mathrm{~cm} \sim 80$ $\mathrm{cm}[14]$. Four types of ecological restoration mode of soil

\footnotetext{
* Corresponding author: mksrh@126.com
} 
and water conservation were used on the mining wasteland, including that shrub, shrub + grass, ecological bag + grass, sand barrier + grass. The area of each test plot was $20 \mathrm{~m} \times 5 \mathrm{~m}$. Saw Table 1 for the plot setting of the comprehensive mode of soil and water conservation.

Table 1. Setting of test sample area.

\begin{tabular}{|c|c|c|}
\hline $\begin{array}{c}\text { Test } \\
\text { area }\end{array}$ & $\begin{array}{c}\text { Ecological } \\
\text { Restoration } \\
\text { Mode }\end{array}$ & Mode configuration form \\
\hline No.1 & shrub & $\begin{array}{c}\text { Artificially planted Caragana } \\
\text { korshinskii with a row spacing of } \\
1.5 \mathrm{~m} \times 1.5 \mathrm{~m} \text { and } 2 \text { to } 3 \text { plants per } \\
\text { hole }\end{array}$ \\
\hline No.2 & shrub + grass & $\begin{array}{c}\text { Artificially planted Caragana } \\
\text { korshinskii } \text { with a row spacing of } \\
1.5 \mathrm{~m} \times 1.5 \mathrm{~m} \text { and } 2 \text { to } 3 \text { plants per } \\
\text { hole, sowing Medicago sativa and } \\
\text { Elymus dahuricus }\end{array}$ \\
\hline No.3 & ecological \\
bag + grass & $\begin{array}{c}\text { The ecological bags filled with soil } \\
\text { were fixed on the slope, and the } \\
\text { vertical distance between the } \\
\text { ecological bags was } 1 \mathrm{~m} \text {. Sowing } \\
\text { Medicago sativa } \text { and Elymus } \\
\text { dahuricus in the open space of the } \\
\text { ecological bag }\end{array}$ \\
\hline No.4 & $\begin{array}{c}\text { sand barrier }+ \\
\text { grass }\end{array}$ & $\begin{array}{c}\text { Set a } 1 \mathrm{~m} \times 1 \mathrm{~m} \text { diamond grid sand } \\
\text { barrier with Tamarix ramosis, } \\
\text { Sowing Medicago sativa } \text { and } \\
\text { Elymus dahuricus in the open space } \\
\text { of the sand barrier }\end{array}$ \\
\hline
\end{tabular}

\subsection{Methods}

The plant growth status, wind erosion resistance, water storage and soil retention capacity of each test area were measured.

\subsubsection{Vegetation survey}

The soil and water conservation measures were deployed in the third year of vigorous plant growth period (early August), and the sample method was used for vegetation survey. Three plots $(1 \mathrm{~m} \times 1 \mathrm{~m})$ were randomly selected in each test plot, and the height, cover, and shrub crown diameter of each plant in each plot were determined. The aboveground biomass of plant communities was determined by the method of cutting. Cut the plants in the plot uniformly, and stubble the height of about $1 \mathrm{~cm}$. After cutting, the plants are placed in the drying box without distinguishing the species. The plants are dried to constant weight in the drying box for about 24-48 hours. The dry weight is weighed with a $0.01 \mathrm{~g}$ balance after cooling.

\subsubsection{Determination of soil wind erosion}

The wind erosion disk method was used to determine the amount of soil wind erosion. Three monitoring points were arbitrarily selected in the test sample area. The three points formed an equilateral triangle with a side length of $15 \mathrm{~m}$, and a wind erosion disk was set at each of the three vertices of the triangle. The weight of the wind erosion disk was observed once a month during the wind season and the soil wind erosion modulus was calculated.

\subsubsection{Determination of soil water erosion}

A water outlet was set at the lowest part of each test sample area, and a collecting barrel was installed at the outlet end with a volume of $0.13 \mathrm{~m} 3$, which was used to collect runoff and sediment produced by one rainfall. After each rainfall runoff, measured the water collection depth (h) in the bucket and calculated the total volume of runoff on the slope. Obtained a sample with a full-depth profile sampler, representing the total representative water sample of this runoff, and weighing its weight and volume. After filtering, the sample was dried at $105^{\circ} \mathrm{C}$ to a constant weight. The electronic balance weighed its mass and calculated the runoff and erosion of the rainfall.

\section{Results and analysis}

\section{1 plant growth of Different patterns}

The analysis results of vegetation change inmining wastelandslope under different modes show that the vegetation preservation rate of plot 1 and plot 3 is low. Some herbs appear in plot 1 , the vegetation coverage is $31 \%$ (Fig 1). Due to the ecological bags laid in plot 3, the vegetation coverage has increased compared with plot 1 , the vegetation coverage is $49 \%$, but it is still at a relatively low level. Both plots have a large area of bare surface. The "shrub + grass" mode (plot 2) and the "sand barrier + grass" mode (plot 4) have good plant growth, with plant cover of over $60 \%$ and bare surface area of less than $20 \%$.

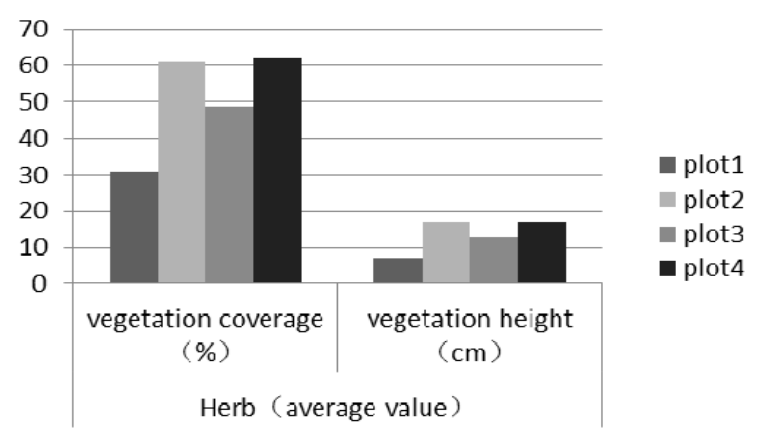

Fig. 1. Vegetation growth in different modes.

\subsection{Change of wind erosion}

The results of soil wind erosion monitoring show that the soil wind erosion thickness in each test area is quite different after the implementation of soil and water conservation measures(Fig 2). Each plot is ranked as follows according to the measured results of wind erosion resistance, plot $4>$ plot $2>$ plot $3>$ plot 1 . The amount of soil wind erosion in plot 2 is close to that in plot 4 , and the reduction range is $30-85 \%$ compared with the other two plots. The difference between plot 2 and plot 4 and plot 1 and plot 3 is significant $(p<0.05)$, 
indicating that the measure configuration mode of plot 2 and plot 4 is stronger than other sample areas.

$$
\text { soil wind erosion }\left(\mathrm{t} / \mathrm{hm}^{2}\right)
$$

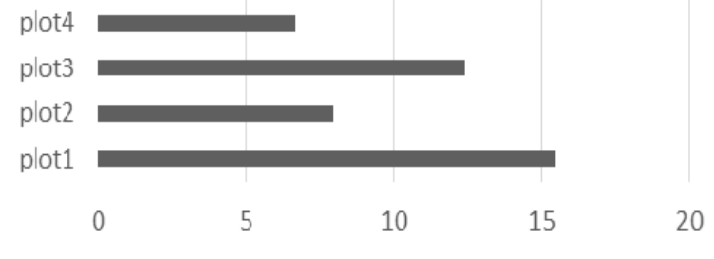

Fig. 2. Changes of soil wind erosion in different modes.

\subsection{Change of soil water erosion}

The amount of soil water erosion in plot 3 (ecological bag + grass) is the smallest, $77 \%$ of plot 1 (shrub), followed by plot 4 (sand barrier + grass), the amount of soil water erosion is $82 \%$ of plot 1 in the first year of the ecological restoration mode. The amount of soil water erosion in plot 3 and plot 4 is significantly smaller than that of other modes, which has a significant effect of blocking water storage and reducing surface runoff. The main reason is that the slope is covered by the ecological bag and sand barrier interval, which slowed down the surface runoff flow, Increased runoff infiltration, played a certain role in soil consolidation, and reduced soil water erosion. In the second year of the implementation of the measure, the annual soil water erosion in each plot decreased to varying degrees compared with the previous year. The difference between the annual soil water erosion in different plots gradually increased. The amount of soil water erosion decreased by more than $30 \%$ compared with the previous year in plot 2 , plot 3 and plot 4 . Plot 3 has the best ability to resist erosion and maintain water and soil, Plot 2 and Plot 4 are second, but both are significantly better than Plot 1 . The comparative analysis of the above test data shows that the effect of soil water erosion control in plot 2, plot 3 and plot 4 mode is better in the dump slope, which can be used as the main ecological restoration mode of soil and water conservation in the wasteland slope of the grassland gold mine. The "sand barrier + grass" mode is especially suitable for abandoned land slopes that are prone to strong wind and water erosion in the early stage of soil cover.

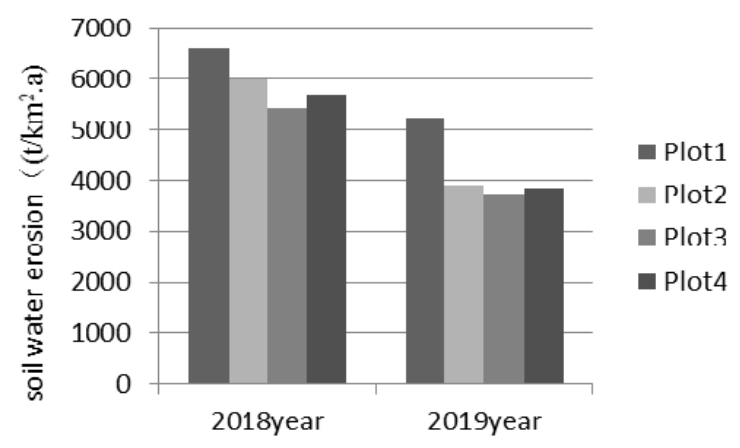

Fig. 3. Comparison of soil water erosion in different modes.

\subsection{Comprehensive benefits of ecological restoration mode of soil and water conservation}

Considering the economic cost, rank-sum ratio method (RSR) is used to evaluate and analyse the comprehensive benefits of each mode, in order to find a mode suitable for ecological restoration of the soil and water conservation in the wasteland of grassland gold mines. The evaluation indicators are selected to reflect the ecological benefits of the slope (vegetation coverage), to reflect the capacity of water storage and soil retention (soil erosion), and to reflect the economic benefits (investment cost). The evaluation index values of different modes in the study area shows in Table 2 through tests and investigations.

Calculate the RSR value according to the RSR formula.

$$
R S R_{i}=\sum_{j=1}^{m} \frac{R_{i j}}{m \times n}
$$

In the formula, $\mathrm{m}$ is the number of assessment indicators and $\mathrm{n}$ is the number of groups. Sort by RSR value from small to large (Table 2). The larger the RSR value, the higher the comprehensive benefit of the evaluated mode and the smaller the RSR value, the lower the comprehensive benefit of the evaluated mode according to the evaluation principle of rank sum ratio method[15]. The calculation results of RSR value indicate that in the ecological restoration mode of soil and water conservation, the comprehensive benefit rank is: sand barrier + grass $>$ shrub + grass $>$ ecological bag + grass $>$ shrub. "sand barrier + grass" mode and "shrub + grass" mode perform better in the treatment of investment costs and soil and water conservation benefits, and the effect of soil and water loss prevention and control is obvious. Therefore, it should be used preferentially in the ecological restoration of the soil and water conservation of the wasteland of grassland mines.

Table 2. Ranks of vegetation coverage, soil erosion,

\begin{tabular}{|c|c|c|c|c|c|c|c|}
\hline \multirow[b]{2}{*}{ mode } & \multicolumn{6}{|c|}{ comprehensive benefit index } & \multirow[b]{2}{*}{ RSR } \\
\hline & $\begin{array}{l}\text { vegeta } \\
\text { tion } \\
\text { covera } \\
\text { ge }(\%) \\
\end{array}$ & sort & $\begin{array}{c}\text { soil } \\
\text { erosion } \\
\left(\mathrm{t} / \mathrm{km}^{2} \bullet \mathrm{a}\right)\end{array}$ & sort & $\begin{array}{l}\text { Cost } \\
\text { (yuan } \\
\left./ \mathrm{m}^{2}\right)\end{array}$ & sort & \\
\hline shrub & 31 & 1 & 5249 & 1 & 0.2 & 4 & 0.222 \\
\hline $\begin{array}{c}\text { shrub } \\
+ \\
\text { grass }\end{array}$ & 61 & 3.5 & 3910 & 3 & 2.0 & 3 & 0.813 \\
\hline $\begin{array}{l}\text { ecolo } \\
\text { gical } \\
\text { bag }+ \\
\text { grass } \\
\end{array}$ & 49 & 2 & 3746 & 4 & 18 & 1 & 0.680 \\
\hline $\begin{array}{c}\text { sand } \\
\text { barrie } \\
\mathrm{r}+ \\
\text { grass }\end{array}$ & 62 & 4 & 3850 & 3.5 & 3.0 & 2 & 0.795 \\
\hline
\end{tabular}
investment cost index for different modes.

Note: Cost is the survey value, cost $=$ material cost + labor cost. Vegetation coverage and soil erosion are the actual measured values the year after the mode was implemented. 


\section{Conclusion}

4.1 The soil and water conservation and ecological restoration of the abandoned grassland gold mines need to scientifically and rationally set up ecological restoration measures for soil and water conservation according to the characteristics of the production and construction project engineering, combined with the natural climate conditions of the grassland in northern China.

4.2 The ecological restoration mode of soil and water conservation formed by combining biological sand barriers, ecological bags and other engineering measures with plant measures have obvious vegetation restoration effects, significant water and soil conservation benefits, and relatively low economic costs among the more mature water and soil conservation engineering measures. It is suitable for popularization and application in ecological restoration of artificial grassland remodeling in northern grasslands with poor natural conditions and difficult vegetation restoration.

4.3 Aiming at the difficult site of the abandoned slope in the northern grassland mining area, the two ecological restoration modes of "sand barrier + grass" and "shrub + grass" can achieve better prevention and control of soil erosion.

\section{Acknowledgments}

This work was supported by Major Special Science and Technology Project of Inner Mongolia Autonomous Region (zdzx2018058) and Inner Mongolia Autonomous Region Science and Technology Plan Project (2019GG023).

\section{References}

1. CHEN Laihong, MA Wanli. Discussion on vegetation restoration and reconstruction in dumping site of open coal mine in huolinhe. Science of Soil and Water Conservation,2011, 9(4): 117-120.

2. WANG Keqin, ZHAO hui, GAO Tiantian, et al,. Influence grades of soil and water loss resulted by production and construction projects. Bulletin of soil and water conservation,2015, 35(3): 143-148.

3. SHI Dongmei. Study on eroded environment and its soil and water loss characteristics during expressway construction. Journal of Soil and Water Conservation,2006, 20(2): 5-9.

4. WANG Keqin, JIANG Dewen, GAO Tiantain, et al, A study on comprehensive index of soil and water loss of production and construction projects using analytic hierarchy process. Bulletin of Soil and Water Conservation, 2015, 35(3): 136-142.

5. LU Zhao, WANG Dongmei, XU Zhiyou, et al,. Soil erosion characteristic and prevention measures in abandoned dreg (soil) field of production and construction. Science of Soil and Water Conservation, 2013, 11(3): 118-126.

6. BAI Zhongke, ZUO Xun, GUO Qingxia, et al,. Study on land reclamation planning in large-scale opencast coal mine. Journal of Soil and Water Conservation, 2001, 15(4): 118-121

7. LIU Siying. The ecological restoration technology system of wter conservation in Heidaigou surface soil. LIAONING Technical University, 2012.

8. XV Lilin. Experimental study on soil improvement and plant selection for ecological regeneration in drought mining area. China University of Mining and Technology, 2014.

9. Jianjun Zhang, Meichen Fu, Ferri P. Hassani, et al. Land use-based landscape planning and restoration in mine closure areas[J]. Environmental Management, 2011,47: 739-750.

10. MENG Qinwei, LI Hongyuan, JU Meiting, et al,. An overview of restoration and reconstruction of damaged ecosystem in Europe. Bulletin o soil and Water Conservation, 2008, 28(5): 201-208.

11. Yuri Gorokhovich, Andrew Voros, Matthew Reid, et al. Prioritizing abandoned coal mine reclamation projects within the contiguous United States using geographic information system extrapolation. Environmental Management, 2003,32 (4):527-534.

12. CHEN Xiaoqin, ZHAO Fangying. Quantitative classification and ordination of natural vegetation on abandond mine land in Mentougou district, Beijing. Journal of Northeast Forestry University, 2010, 38(11): 75-79.

13. LU Gang, HUANG Long, WANG Honglu. Spatial variability characteristics of soil anti-scourability on the slope of a dump. Journal of Southwest University(Natural Science Edition), 2013, 35(1): 35-42.

14. Liu W M, Xing W S. Study on the mining technology of the two open pit mine. Opencast Mining Technology, 2009, 4: 14-16.

15. Yu Chenggang, Su Bingjing. A non-parametric sequential rank-sum probability ratio test method for binary hypothesis testing[J]. Signal Processing, 2004, 84(7):1267-1272. 